\title{
Behavioral and Neurochemical Recovery from Partial 6- Hydroxydopamine Lesions of the Substantia Nigra Is Blocked by Daily Treatment with D1/D5, But Not D2, Dopamine Receptor Antagonists
}

\author{
Adriana Emmi, Heshmat Rajabi, and Jane Stewart \\ Center for Studies in Behavioral Neurobiology, Department of Psychology, Concordia University, Montreal, Quebec, \\ Canada H3G 1 M8
}

\begin{abstract}
To determine whether D1/D5 dopamine (DA) receptors play a role in normalization of DA extracellular levels of striatal DA and behavioral recovery after partial 6-OHDA lesions of the substantia nigra, animals were treated on days 1-8 after lesioning with the D1/D5 DA receptor antagonists SCH 23390 (0.1 mg/ $\mathrm{kg}$, s.c.) and SCH 39166 (1.0 mg/kg, s.c.), the inactive enantiomer SCH $23388(0.1 \mathrm{mg} / \mathrm{kg}$, s.c.), the D2 antagonist eticlopride $(0.1 \mathrm{mg} / \mathrm{kg}$, i.p.), or saline. Spontaneous turning behavior was assessed on days 3 and 15. Basal extracellular DA and metabolites were measured in both striata using microdialysis on days 16 and 17, 8-9 d after termination of drug treatments. On day 3, all animals turned ipsilateral to the lesion. On day 15, animals previously treated with either saline, eticlopride, or $\mathrm{SCH} 23388$ showed no behavioral asymmetries, whereas ani-
\end{abstract}

mals treated with SCH 23390 or SCH 39166 turned ipsilaterally. On days 16 and 17, extracellular DA did not differ on the two sides in animals treated with saline or eticlopride and were higher on the lesioned side after $\mathrm{SCH}$ 23388. In animals treated with the D1/D5 receptor antagonists, however, basal levels of DA were lower on the lesioned side, showing no evidence of normalization. These results suggest a role for the D1/D5 DA receptor in the development of compensatory changes in the DA neurons that accompany behavioral recovery from partial lesions of nigrostriatal DA system.

Key words: substantia nigra; 6-OHDA lesions; behavioral recovery; striatal dopamine; microdialysis; D1/D5 receptor antagonists; D2 receptor antagonists
Behavioral recovery after partial unilateral lesions of the nigrostriatal pathway is accompanied by gradual normalization of extracellular dopamine (DA) in the striatum measured using microdialysis (Robinson and Whishaw, 1988; Zhang et al., 1988; Abercrombie et al., 1990; Castañeda et al., 1990; Robinson et al., 1994). We showed recently that daily injections of NMDA receptor antagonists given in the first week after such lesions block behavioral recovery and normalization of extracellular DA in striatum measured 1 week after the last drug injections using microdialysis (Emmi et al., 1996). We argued on the basis of our findings that glutamate acts immediately after a lesion, in a period with high potential for neural plasticity, to bring about enduring changes in functioning of the DA neurons that remain after partial lesions. These findings led us to compare the compensatory changes that seem to occur in the remaining DA neurons with the changes responsible for sensitization within the midbrain DA system that occurs after repeated injections of amphetamine. Several days to weeks after termination of amphetamine treatments (Kolta et al., 1985; Kalivas and Duffy, 1993; Paulson and Robinson, 1995), there is increased dopaminergic activity in striatal regions: higher basal levels of DA metabolites, and higher extracellular DA levels in response to amphetamine challenge

Received Dec. 23, 1996; revised Feb. 18, 1997; accepted Feb. 21, 1997.

This research was funded by grants to J.S. from the Medical Research Council of Canada and from the Fonds pour la Formation de Chercheurs et l'Aide à la Recherche (Québec).

Correspondence should be addressed to Jane Stewart, Center for Studies in Behavioral Neurobiology, Department of Psychology, Concordia University, 1455 de Maisonneuve Boulevard West, Montreal, Quebec, Canada H3G 1M8.

Copyright (C) 1997 Society for Neuroscience $0270-6474 / 97 / 173840-07 \$ 05.00 / 0$
(Robinson et al., 1988; Akimoto et al., 1990; Patrick et al., 1991; Vezina, 1993). These long-lasting neuronal changes that accompany behavioral sensitization of the effects of amphetamine suggest a permanent reorganization within the system. It was of interest that, as is the case for recovery from partial lesions of the substantia nigra (SN), the development of sensitization to amphetamine is blocked by NMDA receptor antagonists (Karler et al., 1989, 1990; Wolf and Khansa, 1991; Stewart and Druhan, 1993; Wolf and Jeziorski, 1993; Wolf et al., 1994).

The development of sensitization to amphetamine as expressed behaviorally and by increased extracellular DA levels in the ventral striatum in response to amphetamine is also blocked by antagonists of the D1/D5 DA receptor (Vezina and Stewart, 1989; Drew and Glick, 1990; Vezina, 1996). Furthermore, blockade of D1/D5 receptors in the ventral tegmental area (VTA)-SN region, where the events that lead to amphetamine-induced sensitization of DA functioning are initiated (Kalivas and Weber, 1988; Vezina and Stewart, 1990; Vezina, 1993; Cador et al., 1995), is sufficient to produce this effect (Stewart and Vezina, 1989; Bjijou et al., 1996). D1/D5 receptors in the VTA and SN reticulata are located on terminals of afferents to these regions arising from the cortex (Dewar et al., 1996) and striatum (Altar and Hanser, 1987; Richfield et al., 1987; Mansour et al., 1992). Stimulation of D1/D5 receptors in the VTA and $\mathrm{SN}$ increases the local release of glutamate (Kalivas and Duffy, 1995) and GABA (Floran et al., 1990; Cameron and Williams, 1993). We speculated, therefore, that DA activity at D1/D5 receptors might also contribute to changes in the nigrostriatal DA system that occur in the period immediately after lesioning. To test this idea, animals were 
treated daily with D1 or D2 receptor antagonists or saline for $8 \mathrm{~d}$ after partial unilateral 6-OHDA SN lesions. Behavioral recovery and normalization of basal DA levels in the striatum were assessed $8 \mathrm{~d}$ after the last injections.

\section{MATERIALS AND METHODS}

\section{Subjects}

Subjects were male Wistar rats weighing 350-380 gm at the beginning of the experiment. The rats were housed individually in plastic shoe box cages with tap water and standard rat chow available ad libitum. The light/dark cycle was reversed (lights off between 8:00 A.M. and 8:00 P.M.), and testing was conducted during the dark phase of the cycle (from 8:00 A.M.).

\section{Drugs}

6-OHDA, SCH $23390 \quad[R(+)$-7-chloro-8-hydroxy-3-methyl-1-phenyl2,3,4,5-tetrahydro-1H-3-benzazepine $\mathrm{HCl}], \mathrm{SCH} 23388[R(-)$-7-chloro8-hydroxy-3-methyl-1-phenyl-2,3,4,5-tetrahydro-1H-3-benzazepine $\mathrm{HCl}$, the inactive enantiomer], and eticlopride [S(-)-chloro-5-ethyl- $N-[(1-$ ethyl-2-pyrrolidinyl)methyl]-6-hydroxy-2 methoxy-benzamide $\mathrm{HCl}]$ were obtained from RBI Biochemicals; SCH 39166 [(-)-trans-6,7,7a,8,9,13bhexahydro-3-chloro - 2 - hydroxy - $N$ - methyl-5H-benzo-[d]naphtho[2,1b] azepine] was from Schering-Plough Research Institute; and desmethylimipramine and pargyline were from ICN Pharmaceuticals Canada, Ltd.

\section{Surgery}

Animals were injected with desmethylimipramine $(15 \mathrm{mg} / \mathrm{kg}$, i.p., in 1.0 $\mathrm{ml} / \mathrm{kg}$ saline) $30 \mathrm{~min}$ before lesioning. They were anesthetized with sodium pentobarbital $(30 \mathrm{mg} / \mathrm{kg}$, i.p.) and given injections of atropine sulfate $(0.5 \mathrm{mg} / \mathrm{ml}, 0.1 \mathrm{ml} / \mathrm{rat}$, s.c.) and pargyline $(40 \mathrm{mg} / \mathrm{kg}$, s.c., in 1.0 $\mathrm{ml} / \mathrm{kg}$ saline). Using a stereotaxic instrument set to obtain a flat skull, 6-OHDA ( $8 \mu \mathrm{g} / 4 \mu \mathrm{l}$ of saline) was injected unilaterally into the substantia nigra (anterior-posterior, -5.4 ; lateral, 2.0; dorsal-ventral, -9.3 from the skull surface) using a Hamilton microsyringe; the injector was removed 5 min after the end of the infusion. These injection parameters yield lesions that are estimated to range from 56 to $90 \%$ of the nonlesioned side as measured by tissue levels of DA in the striatum (Emmi et al., 1996).

With the stereotaxic arms angled at $10^{\circ}$ from the vertical plane, 22 gauge stainless steel guide cannulae, for the later insertion of the dialysis probes, were implanted bilaterally into the striatum using the skull surface coordinates of anterior-posterior, +1.2; lateral, 3.0; and dorsalventral, -3.4 . The cannulae were anchored to the skull with stainless steel screws and secured to the surface with dental cement. All animals were injected with penicillin $\mathrm{G}(300,000 \mathrm{IU}, 0.2 \mathrm{ml} / \mathrm{rat})$ after surgery. At the end of the study, animals were killed by decapitation, and the brains were removed, frozen, and sliced. The slices were immediately examined, and the location of the track formed by the probes was determined. Placements were within the striatum in all cases. Only one animal was eliminated from the results on the basis of an infected region around the cannulae.

\section{Behavioral tests}

To increase the probability of sustained behavioral activation without having to treat animals with a stimulant drug, one set of tests was conducted in the home cage at the beginning of the dark cycle when animals are active, and another set was conducted after animals were moved to a novel environment.

Locomotion and turning in home cage. Locomotor activity was measured for $10 \mathrm{~min}$ at the start of the dark phase of the cycle (8:00 A.M.) in the plastic shoe box home cages. A video camera and a videocassette recorder were used to record the behavior. Tapes were scored for the number of $360^{\circ}$ turns ipsilateral or contralateral to the lesion in $10 \mathrm{~min}$. The time spent drinking with one or the other side of the face toward the drinking tube was noted.

Water was available ad libitum, whereas access to food was interrupted during the observation.

Turning and wall facing in the novel environment. After the home cage observation, the behavior was monitored in a novel environment using a video image-analyzing system (Chromotrack System, Poly-track model; San Diego Instruments). Four boxes $(58 \times 58 \times 48 \mathrm{~cm})$ built of wood, painted flat black, and open at the top were used. The video camera was connected to a computer located in a separate room. Using a combination of the software program provided and a record of the video image, behavior was scored for the number of $360^{\circ}$ turns ipsilateral and contralateral to the lesion, and for the total time during which the vibrissae or the body of the moving animal was in contact with the wall of the open field (wall facing) (Steiner et al., 1988). Recording started $10 \mathrm{sec}$ after the rat was placed in the center of the field and lasted $5 \mathrm{~min}$.

\section{Microdialysis}

Microdialysis was conducted in four hexagonal testing chambers $(42 \times$ $39 \times 33.5 \mathrm{~cm}$ ) built from Plexiglas with wooden ceilings and stainless steel rod floors. Dark curtains were drawn around each chamber, and lighting was provided on a reversed cycle by overhead light bulbs $(15 \mathrm{~W})$. The dialysis probe consisted of a $3.5 \mathrm{~mm}$ length of semipermeable dialysis membrane (Spectra/Por; $240 \mu \mathrm{m}$ outer diameter, 13,000 molecular weight cutoff), closed at one end and attached at the other to a $19 \mathrm{~mm}$ length of 26 gauge stainless steel tubing. A 40-50 cm length of PE-20 tubing connected the other end of the stainless steel shaft to an infusion swivel stationed above the testing chamber that was in turn connected via PE-20 tubing to a variable speed infusion pump. A small diameter, fused silica tube extended internally through the probe, with one end resting 0.5 $\mathrm{mm}$ from the tip of the probe and the other end exiting the PE tubing 35 $\mathrm{cm}$ below the infusion swivel. The animals were held and gently rocked before insertion of the probes, which were then secured in place by brass collars that screwed onto the guide cannulae, and the external length of PE-20 tubing was protected from damage by steel spring casings. The probes were designed so that the entire length of semipermeable membrane extended below the guide cannula tip.

The probes were inserted the day before the beginning of microdialysis testing. To prevent occlusion, artificial CSF $\left(145 \mathrm{mM} \mathrm{Na}^{+}, 2.7 \mathrm{mM} \mathrm{K}^{+}\right.$, $1.22 \mathrm{mM} \mathrm{Ca}^{2+}, 1.0 \mathrm{mM} \mathrm{Mg}^{2+}, 150 \mathrm{mM} \mathrm{Cl}^{-}, 0.2 \mathrm{~mm}$ ascorbate, and $2 \mathrm{~mm}$ $\mathrm{Na}_{2} \mathrm{HPO}_{4}$, $\mathrm{pH} 7.4 \pm 0.1$ ) was perfused overnight at a rate of $0.06 \mu \mathrm{l} / \mathrm{min}$.

Dialysate sampling and activity monitoring began the next morning. Half of the animals from each treatment condition were dialyzed on the lesioned side on the first day of dialysis and on the intact side on the second day of dialysis; for the other animals the conditions were reversed. The dialysate flow rate was increased to $0.6 \mu \mathrm{l} / \mathrm{min}$, and baseline dialysate samples $(\sim 12 \mu \mathrm{l} /$ sample) were collected every $20 \mathrm{~min}$. A $10 \mu \mathrm{l}$ volume of dialysate was extracted from each sample and immediately analyzed using one of two similar HPLC systems with electrochemical detection (HPLCEC). The samples were loaded onto reverse-phase columns $(15 \times 0.46$ $\mathrm{cm}$; Spherisorb-ODS2, $5 \mu \mathrm{m}$; Chromatography Sciences) through manual injection ports (Reodyn $7125 ; 20 \mu$ l loop); reduction and oxidation currents for DA and its metabolites dihydrophenylacetic acid (DOPAC) and homovanillic acid (HVA) were measured with dual channel ESA coulometric detectors (Coulochem 5100, with a model 5021 conditioning cell and a model 5011 analytical cell; Scientific Products \& Equipment, Concord, Ontario, Canada). The currents for DA were measured independent of those for DOPAC and HVA using separate channels of the Coulochem detectors. The mobile phases $(25 \%$ methanol, $0.076 \mathrm{~m}$ SDS, $0.1 \mathrm{M}$ EDTA, $0.058 \mathrm{M} \mathrm{NaPO}_{4}$, and $0.27 \mathrm{~m}$ citric acid, $\mathrm{pH} 4.0$ ) were circulated through each closed system at a flow rate of $1.0 \mathrm{ml} / \mathrm{min}$ by Waters 510 HPLC pumps. The peaks obtained for DA, DOPAC, and HVA were integrated and quantified by an EZChrom chromatography data system (Scientific Products \& Equipment). Dialysate samples from individual rats always were analyzed with the same HPLC-EC system, and the assignment of animals to each system was counterbalanced across all treatment groups. Food was removed from the chambers before sampling, but a water drinking tube was available.

\section{Design and procedures}

Figure 1 outlines the timing of the treatments and experimental manipulations. To determine whether D1/D5 or D2 DA receptors played a role in the recovery from partial 6-OHDA lesions of the $\mathrm{SN}$, animals were treated with the D1/D5 DA receptor antagonists $\mathrm{SCH} 23390$ or $\mathrm{SCH}$ 39166 or with the inactive enantimer SCH 23388, with the D2 receptor antagonist, eticlopride, or with saline for the first $8 \mathrm{~d}$ after the lesion (days $1-8)$. Injections of either $0.1 \mathrm{mg} / \mathrm{kg} \mathrm{SCH} 23390$, s.c. $(n=9)$, and 0.1 $\mathrm{mg} / \mathrm{kg} \mathrm{SCH} 23388$, s.c. $(n=9)$, chosen on the basis of previous behavioral studies (Vezina, 1996); $1.0 \mathrm{mg} / \mathrm{kg}$ s.c. of the highly selective D1/5 receptor antagonist SCH $39166(n=5)$, dose chosen on the basis of previous binding analyses and behavioral studies (McQuade et al., 1991); 0.1 $\mathrm{mg} / \mathrm{kg}$ eticlopride, i.p. $(n=12)$, chosen on the basis of its ability to suppress behavioral activation (Hoffman and Donovan, 1994; Jeziorski and White, 1995); or saline, i.p. $(n=6)$, were given daily at 10:00 A.M. On days 3 and 15, behavioral observations were made in both environments before the drug treatments beginning around 8:00 A.M. No injec- 


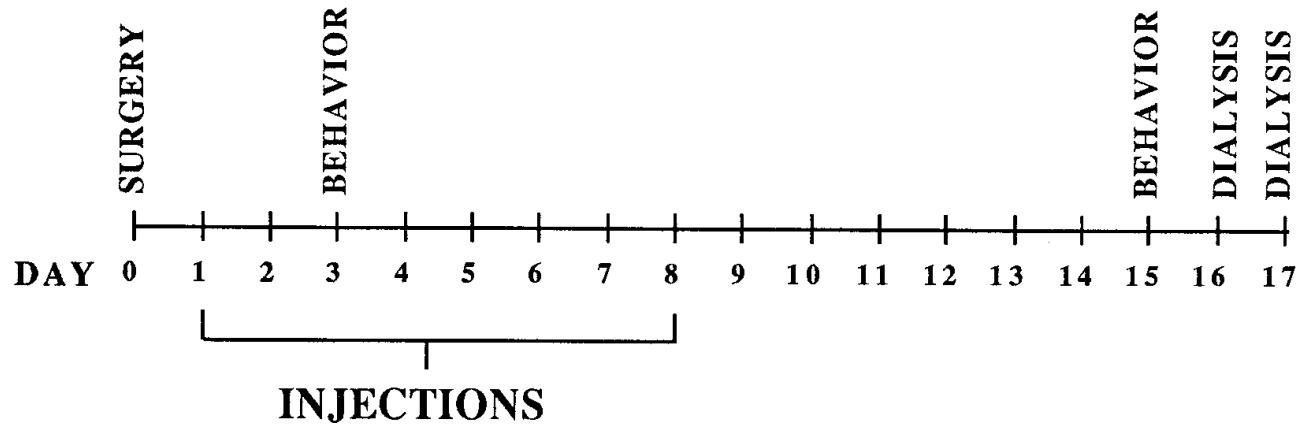

Figure 1. Outline of timing of treatments and experimental manipulations. tions were given on days $9-15$. The animals were moved to the microdialysis chambers after testing on day 15 . The probes were inserted and were perfused overnight at a rate of $<0.06 \mathrm{ml} / \mathrm{min}$. Dialysate sampling began on the morning of day 16 when one-half of the animals from each treatment condition were dialyzed on either the lesioned or the intact side. Several samples were taken and analyzed to determine that the baseline was settled (usually five or six samples at $20 \mathrm{~min}$ intervals) before the final eight samples were taken for statistical analysis. That evening, a probe was inserted into the other striatum, and on day 17 dialysate sampling began in the morning after similar procedures.

\section{Statistical analyses}

The data from all animals (with the exception mentioned in Surgery) were included in the analyses. The data from microdialysis, performed on both sides of the brain in all animals, were subjected to two-way ANOVAs for "treatment group" as the between factor and "side" as the within factor. Tests for simple main effects were used to determine the sources of the significant Treatment Group $\times$ Side interactions. The data from the behavioral tests were analyzed by three-way ANOVAs for treatment group as the between factor and side and "time" as within factors. Tests for simple main effects were used to determine the sources of the significant Treatment Group $\times$ Side interactions at each Time.

\section{RESULTS}

\section{In vivo microdialysis Dopamine}

Basal levels of DA from the intact and lesioned striata of animals treated from days 1 to 8 with SCH 23390, SCH 23388, SCH 39166, eticlopride, or saline and then tested using microdialysis on days 16 and 17 ( 8 and $9 \mathrm{~d}$ after termination of drug injections) are shown in Figure $2 A$. It can be seen that animals treated with the saline or with the D2 DA antagonist showed normalization of basal dopamine levels on the lesioned side. On the other hand, animals treated previously with the D1/D5 DA receptor antagonists, SCH 23390 or SCH 39166, had significantly lower basal levels of DA in the striatum on the lesioned side than on the intact side. Animals treated with SCH 23388, the inactive enantiomer of SCH 23390, showed higher basal levels of DA in the striatum on the lesioned side than on the nonlesioned side. These effects are reflected in a significant Treatment Group $\times$ Side interaction.

\section{DOPAC and HVA}

Basal levels of both DOPAC and HVA taken on days 16 and 17 are shown in Figure 2, $B$ and $C$, respectively. The ANOVA showed that there was a significant effect of side, but no Treatment Group $\times$ Side interaction. It can be seen that levels of both metabolites were significantly lower on the lesioned side in all groups, indicating that all groups sustained lesions of similar magnitude (Robinson and Whishaw, 1988; Castañeda et al., 1990). See legend of Figure 2 for results of statistical analyses.

\section{Behavior}

\section{Home cage}

Figure $3 A$ shows that on day 3 all animals in all groups made a greater number of $360^{\circ}$ turns toward the lesioned side (Fig. $3 A$,
Ipsi). By day 15, although all animals displayed an increase in the total number of turns, animals previously treated with SCH 23388, eticlopride, or saline turned equally in both directions. $\mathrm{SCH}$ 23390- and SCH 39166-treated animals, however, continued to turn preferentially toward the lesioned side. These findings are reflected in the significant interaction between Treatment Group $\times$ Side $\times$ Time.

\section{New environment}

Similar results were found for turning in the novel environment. It can been seen in Figure $3 B$ that on day 3 animals in all treatment groups turned predominantly toward the lesion side. By day 15 , saline-, SCH 23388-, and eticlopride-treated animals showed no preferential turning, whereas animals previously treated with the D1/D5 DA receptor antagonists SCH 23390 and SCH 39166 continued to turn more frequently toward the lesioned side. Figure $3 C$ shows the amount of time the vibrissae or the body of the moving animal was in contact with the wall of the open field. On day 3, regardless of treatment condition, animals spent more time with the lesioned side toward the wall. By day 15, saline-, SCH 23388-, and eticlopride-treated animals did not show preference for either side, whereas the SCH 23390- and SCH 39166treated animals continued to keep the lesioned side toward the wall. These effects are reflected in a significant Treatment Group $\times$ Side $\times$ Time interaction. See legend of Figure 3 for results of statistical analyses.

\section{DISCUSSION}

The purpose of these experiments was to determine whether activity at D1/D5 DA receptors plays a role in the changes that lead to the recovery of behavioral function and normalization of striatal basal levels of DA after partial lesion of DA neurons in the substantia nigra. We found that daily injections of the D1/D5 receptor antagonists SCH 23390 and SCH 39166, given for $8 \mathrm{~d}$ after partial 6-OHDA lesions of the nigrostriatal neurons, blocked the behavioral recovery and resulted in low basal levels of striatal DA on the lesioned side of the brain. Neither the D2 DA receptor antagonist nor the inactive enantiomer of the D1/D5 antagonist $\mathrm{SCH} 23388$ interfered with these measures of recovery. These effects were seen $16 \mathrm{~d}$ after the lesions, $8 \mathrm{~d}$ after the termination of drug treatments. Thus, it seems likely that action at D1/D5 receptors in the period immediately after a lesion, when the potential for plastic changes is high, can bring about enduring changes in functioning of the DA neurons that remain after partial lesions. Inexplicably, in the case of the group treated with the inactive enantiomer SCH 23388, basal levels of striatal DA on the lesioned side actually exceeded those seen on the nonlesioned side, despite the fact that the levels of DOPAC and HVA clearly indicated the presence of lesions comparable with those seen in the other groups. This effect of SCH 23388 was seen in seven of 


\section{A. Basal Dopamine}

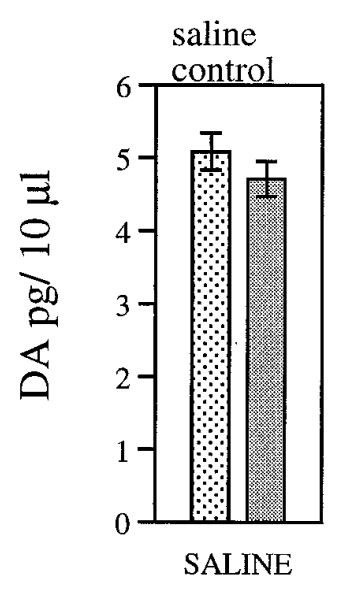

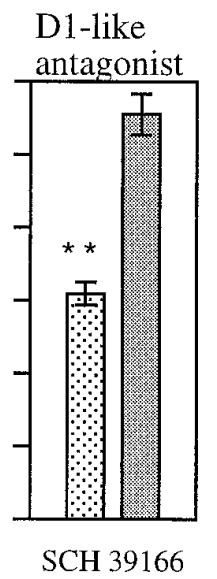

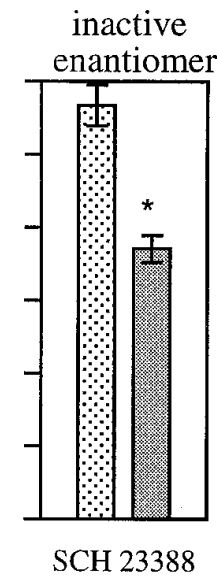

D2-like

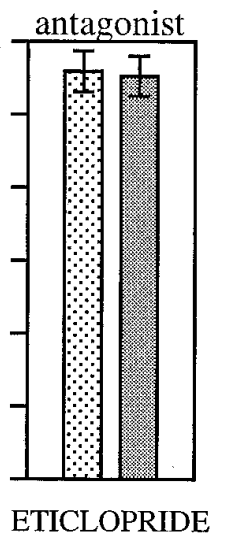

\section{B. Basal DOPAC}
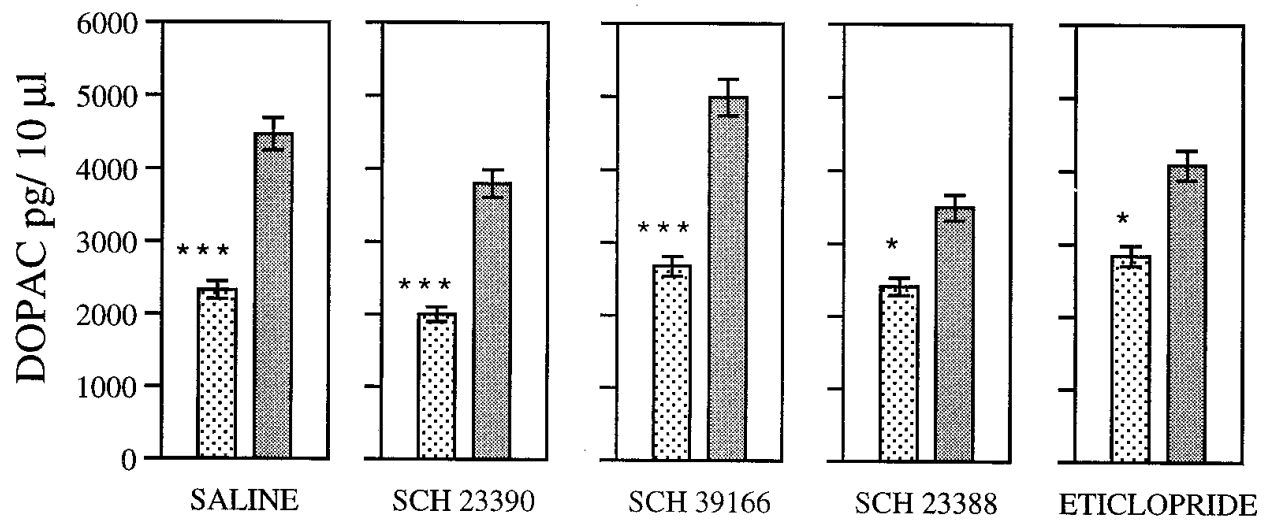

Figure 2. Microdialysis. Mean \pm SEM basal levels of DA $(A)$, DOPAC $(B)$, and HVA $(C)$ in $\mathrm{pg} / 10 \mu \mathrm{l}$ of eight dialysate samples taken at 20 min intervals on the lesioned and intact side of the striatum on days 16 and 17 after surgery in animals with unilateral 6-OHDA lesions in substantia nigra. Treatment groups were given injections of an antagonist or saline daily on days 1-8 after surgery. ANOVAs (Treatment $\times$ Side) yielded the following significant effects: DA, Treatment $\times$ Side interaction $\left[F_{(4,36)}=5.75, p<0.001\right]$; DOPAC, side $\left[F_{(1,36)}=57.22, p<\right.$ $0.0001]$; and HVA, side $\left[F_{(1,36)}=23.17\right.$, $p<0.0001] . *, p<0.05 ; * *, p<0.01 ; * *$, $p<0.001$ (significance of differences between lesioned and nonlesioned sides as assessed by analyses for simple main effects in treatment group).

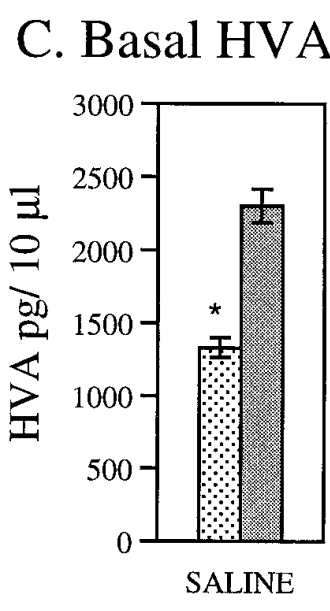

nine of the animals tested (two showed normalization of levels on the lesioned side) and is, therefore, unlikely the result of an experimental artifact. We can only suggest that this compound has partial agonist activity or, more probably, actions at as yet unidentified receptors.

As mentioned in the introductory remarks, these experiments were prompted by the similarities between the compensatory changes in DA neurons after partial lesions and the development of long-term changes in DA neurons after repeated exposure to
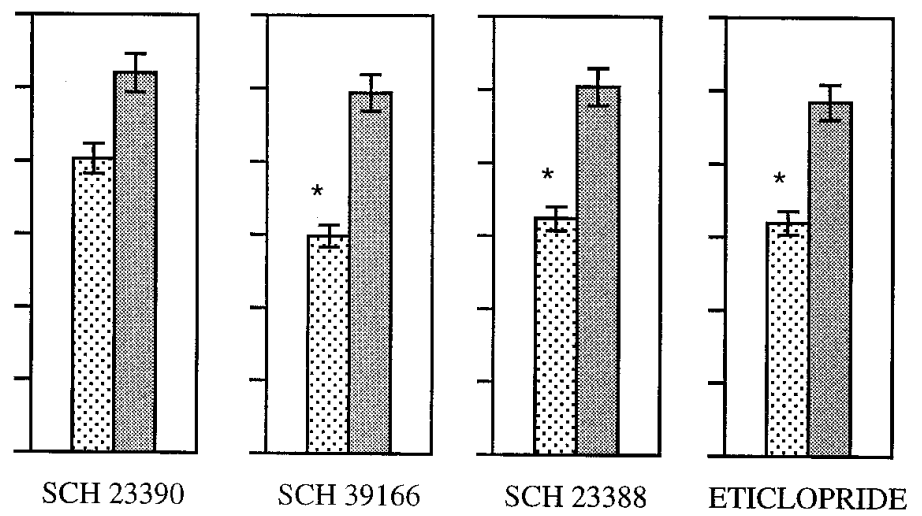

amphetamine. As in the case of sensitization (Karler et al., 1989, 1990; Wolf and Khansa, 1991; Stewart and Druhan, 1993; Wolf and Jeziorski, 1993; Wolf et al., 1994), NMDA receptor antagonists are able to interfere with recovery from partial lesions (Emmi et al., 1996). D1/D5 DA receptor antagonists also interfere with the development of sensitization when given before each injection of amphetamine (Vezina and Stewart, 1989; Drew and Glick, 1990; Vezina, 1996), and there is one report that the antagonist interferes with the development of sensitization when 


\section{A. Home Cage}

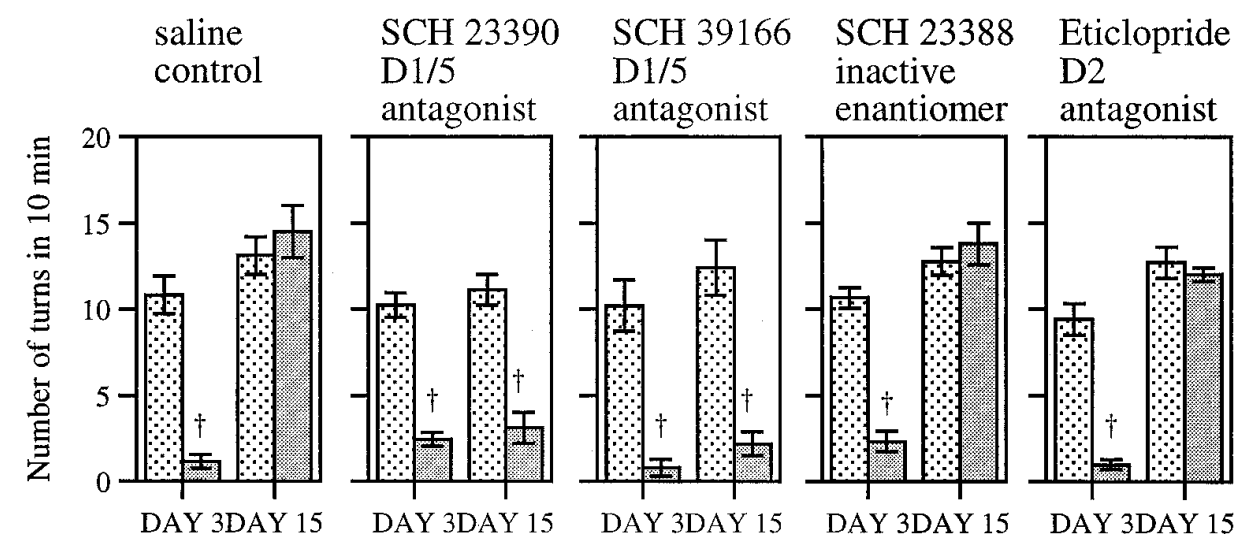

\section{B. New Environment}
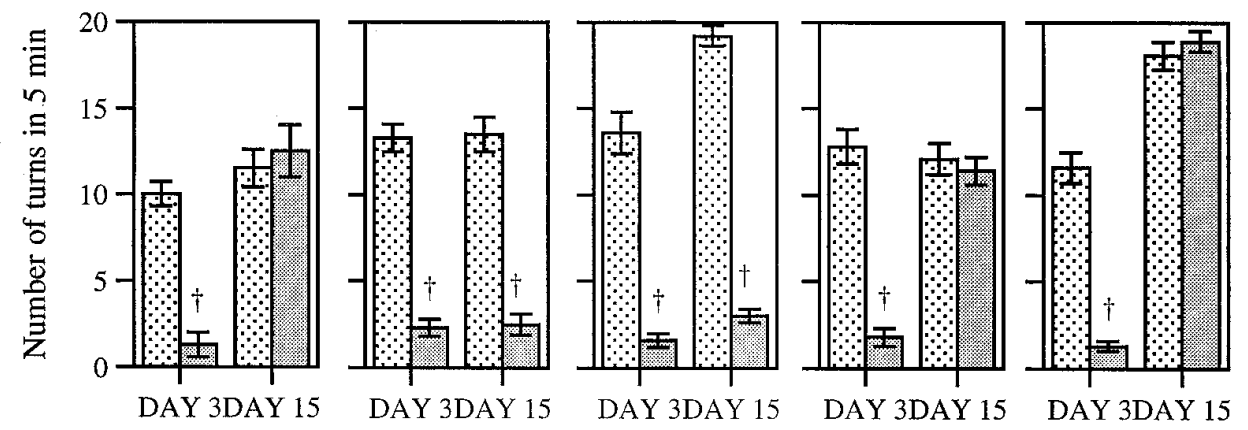

\section{Wall Facing}
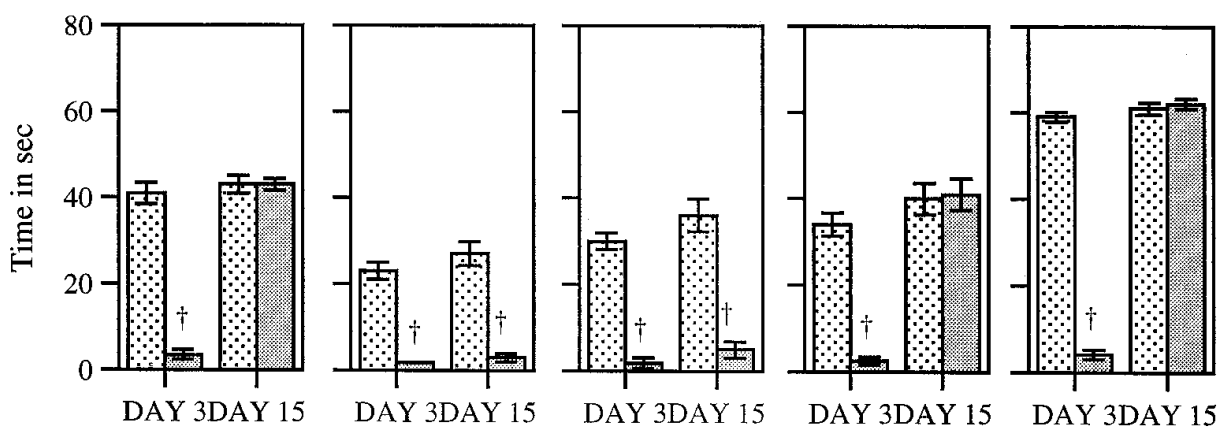

Figure 3. Behavior. Mean \pm SEM number of turns toward the side of the lesion (Ipsi) or away from the lesion (Contra) in tests made on days 3 and 15 after surgery in the home cage $(A)$ and in a new environment $(B)$. C, Mean \pm SEM time the vibrissae or the body of the moving animal was in contact with the wall in the new environment. Treatment groups were given injections of an antagonist or saline daily on days $1-8$ after surgery. ANOVAs (treatment group $\times$ side $\times$ time): In each of the analyses ( $A$, home cage; $B$, new environment; and $C$, wall facing), the main effects of Treatment Group, Side, and Time and all of the interactions were significant $(p=0.0001) . \dagger, p<0.0001$ (significance of differences between number of ipsilateral and contralateral turns as assessed by analyses for simple main effects in each treatment group at each time point).

given after each injection of amphetamine (Kuribara, 1995). Now we show that these compounds can prevent behavioral recovery and normalization of basal levels of DA in the striatum.

The present studies do not allow us to specify where in the system these antagonists are acting to prevent recovery from the lesions. It is known, for example, that after 6-OHDA lesions there are long lasting changes in sensitivity to the behavioral effects of
D1/D5 agonists (Criswell et al., 1989; Criswell et al., 1990). In the case of sensitization to amphetamine there are long lasting increases in the responsiveness of D1 receptors on cells in the ventral striatum as measured electrophysiologically in anesthetized animals (Henry and White, 1991). We know as well, however, from our studies on sensitization, that blockade of D1/D5 receptors in the VTA-SN region is sufficient to prevent sensitiza- 
tion to the behavioral effects of amphetamine (Stewart and Vezina, 1989; Bjijou et al., 1996). D1/D5 receptors found in the VTA and SN reticulata are located on terminals of afferents to these regions arising from the cortex (Dewar et al., 1996) and striatum (Altar and Hanser, 1987; Richfield et al., 1987; Mansour et al., 1992). Stimulation of D1/D5 receptors in the VTA and SN have been shown to increase the local release of glutamate (Kalivas and Duffy, 1995) and GABA (Floran et al., 1990; Cameron and Williams, 1993). Furthermore, locally applied D1/D5 receptor agonists and DA released from dendrites have behavioral effects and can modulate the firing of pars compacta neurons (Waszczak and Walters, 1986; Martin and Waszczak, 1994; Timmerman and Abercrombie, 1996). It is of interest that 6-OHDAlesioned animals seem supersensitive to these effects of DA in the SN (Waszczak and Walters, 1984), and it has been suggested (see Robertson, 1992) that L-DOPA converted to DA may act on $\mathrm{D} 1 / \mathrm{D} 5$ receptors in the $\mathrm{SN}$ to bring about behavioral changes in the 6-OHDA unilateral lesion model of Parkinson's disease.

Finally, the question arises, if both glutamate acting at NMDA receptors and DA acting at D1/D5 DA receptors are involved in long-term compensatory changes in DA neurons that accompany recovery from partial lesions and the development of sensitization after repeated exposure to amphetamine and other stimulant drugs, what is the basis of the interaction between these two systems, and where does the interaction take place? We hypothesized in the case of glutamate that it could act via NMDA receptor activation to stimulate release of DA from dendrites, thereby increasing extracellular DA in the somatodendritic region of the DA neurons. As discussed above, DA acting at D1/D5 receptors in the region can facilitate the release of glutamate, but there is also evidence that DA acting at D1/D5 receptors may enhance NMDA channel function directly (Levine et al., 1996), suggesting another mode of potential interaction between the two systems. It is of interest that there have been recent reports of D1/D5 DA and NMDA receptor interactions in long-lasting neuronal changes involved in long-term potentiation (Huang and Kandel, 1995; Otmakhova and Lisman, 1995) and long-term depression (Chen et al., 1995) in the hippocampus. Thus, one way in which activity at D1/D5 receptors could act to bring about longlasting changes in intracellular events that control DA synthesis and availability in striatal terminal regions (Robinson and Becker, 1986; Vezina, 1993; Vezina, 1996) is through learning-type modifications either within afferents to the DA cells or between the afferents and the somatodendritic region of the DA cells within the substantia nigra (Kalivas and Stewart, 1991; Kalivas, 1995).

\section{REFERENCES}

Abercrombie ED, Bonatz AE, Zigmond MJ (1990) Effects of L-DOPA on extracellular dopamine in striatum of normal and 6-hydroxydopamine-treated rats. Brain Res 525:36-44.

Akimoto K, Hamamura T, Kazahaya Y, Akiyama K, Otsuki S (1990) Enhanced extracellular dopamine level may be the fundamental neuropharmacological basis of cross-behavioral sensntization betweeen methamphetamine and cocaine: an in vivo dialysis study in freely moving rats. Brain Res 507:344-346.

Altar CA, Hanser K (1987) Topography of substantia nigra innervation by D1 receptor-containing striatal neurons. Brain Res 410:1-11.

Bjijou Y, Stinus L, Le Moal M, Cador M (1996) Evidence for a selective involvement of dopamine D1 receptors of the ventral tegmental area in the behavioral sensitization induced by intra-ventral tegmental area injections of D-amphetamine. J Pharmacol Exp Ther 277:1177-1187.

Cador M, Bjijou Y, Stinus L (1995) Evidence of a complete independence of the neurobiological substrates for the induction and expression of behavioral sensitization to amphetamine. Neuroscience 65:385-395.
Cameron DL, Williams JT (1993) Dopamine D1 receptors facilitate transmitter release. Nature 366:344-347.

Castañeda E, Whishaw IQ, Robinson TE (1990) Changes in striatal dopamine neurotransmission assessed with microdialysis following recovery from a bilateral 6-OHDA lesion: variation as a function of lesion size. J Neurosci 10:1847-1854.

Chen Z, Fujii S, Ito K-I, Kato H, Kaneko K, Miyakawa H (1995) Activation of dopamine D1 receptors enhances long-term depression of synaptic transmission induced by low frequency stimulation in rat hippocampus CA1 neurons. Neurosci Lett 188:195-198.

Criswell H, Mueller RA, Breese GR (1989) Priming of D1-dopamine receptor responses: long-lasting behavioral supersensitivity to a D1dopamine agonist following repeated administration to neonatal 6-OHDA-lesions rats. J Neurosci 9:125-133.

Criswell HE, Mueller RA, Breese GR (1990) Long-term $\mathrm{D}_{1}$-dopamine receptor sensitization in neonatal 6-OHDA-lesioned rats is blocked by an NMDA antagonist. Brain Res 512:284-290.

Dewar K, Rompré P-P, Stewart J, Warren RA (1996) Excitotoxic lesions of the medial prefrontal cortex reduce dopamine D1-like binding sites in the ventral tegmental area. Abstr Soc Neurosci 22:828.

Drew KL, Glick SD (1990) Role of D1 and D2 receptor stimulation in sensitization to amphetamine-induced circling behavior and in expression and extinction of the Pavlovian conditioned response. Psychopharmacology 101:465-471.

Emmi A, Rajabi H, Stewart J (1996) Behavioral and neurochemical recovery from partial 6-hydroxydopamine lesions of the substantia nigra is blocked by daily treatment with glutamate receptor antagonists, MK-801 and CPP. J Neurosci 16:5216-5224.

Floran B, Aceves J, Sierra A, Martinez-Fong D (1990) Activation of D1 dopamine receptors stimulates the release of GABA in the basal ganglia of the rat. Neurosci Lett 116:136-140.

Henry DJ, White FJ (1991) Repeated cocaine administration causes persistent enhancement of D1 dopamine receptor sensitivity within the rat nucleus accumbens. J Pharmacol Exp Ther 258:882-890.

Hoffman DC, Donovan H (1994) D1 and D2 dopamine receptor antagonists reverse prepulse inhibition deficits in an animal model of schizophrenia. Psychopharmacology 115:447-453.

Huang Y-Y, Kandel ER (1995) D1/D5 receptor agonists induce a protein synthesis-dependent late potentiation in the CA1 region of the hippocampus. Proc Natl Acad Sci USA 92:2446-2450.

Jeziorski M, White FJ (1995) Dopamine receptor antagonists prevent expression, but not development, of morphine sensitization. Eur J Pharmacol 275:235-244.

Kalivas PW, Duffy P (1995) D1 receptors modulate glutamate transmission in the ventral tegmental area. J Neurosci 15:5379-5388.

Kalivas PW (1995) Interactions between dopamine and excitatory amino acids in behavioral sensitization to psychostimulants. Drug Alcohol Depend 37:95-100.

Kalivas PW, Duffy P (1993) Time course of extracellular dopamine and behavioral sensitization to cocaine. I. Dopamine axon terminals. J Neurosci 13:266-275.

Kalivas PW, Stewart J (1991) Dopamine transmission in the initiation and expression of drug- and stress-induced sensitization of motor activity. Brain Res Rev 16:223-244.

Kalivas PW, Weber B (1988) Amphetamine injection into the A10 dopamine region sensitizes rats to peripheral amphetamine and cocaine. J Pharmacol Exp Ther 245:1095-1102.

Karler R, Calder LD, Chaudhry IA, Turkanis SA (1989) Blockade of "reverse tolerance" to cocaine and amphetamine by MK-801. Life Sci 45:599-606.

Karler R, Chaudhry IA, Calder LD, Turkanis SA (1990) Amphetamine behavioral sensitization and the excitatory amino acids. Brain Res 537:76-82.

Kolta MG, Shreve P, De Souza V, Uretsky NJ (1985) Time course of the development of the enhanced behavioral and biochemical responses to amphetamine after pretreatment with amphetamine. Neuropharmacology 24:823-829.

Kuribara H (1995) Inhibition of methamphetamine sensitization by postmethamphetamine treatment with SCH 23390 or haloperidol. Psychopharmcology 119:34-38.

Levine MS, Li Z, Cepeda C, Cromwell HC, Altemus KL (1996) Neuromodulatory actions of dopamine on synaptically-evoked neostriatal responses in slices. Synapse 24:65-78.

Mansour A, Meador-Woodruff JH, Zhou Q, Civelli O, Akil H, Watson SJ (1992) A comparison of D1 receptor binding and mRNA in rat brain 
using receptor autoradiographic and in situ hybridization techniques. Neuroscience 46:959-971.

Martin LP, Waszczak BL (1994) D1 agonist-induced excitation of substantia nigra pars reticulata neurons: mediation by D1 receptors on striatonigral terminals via a pertussis toxin-sensitive coupling pathway. J Neurosci 14:4494-4506.

McQuade RD, Duffy RA, Anderson CC, Crosby G, Coffin VL, Chipkin RE, Barnett A (1991) [ $\left.{ }^{3} \mathrm{H}\right] \mathrm{SCH} 39166$, a new D1-selective radioligand: in vitro and in vivo binding analyses. $\mathrm{J}$ Neurochem 57:2001-2010.

Otmakhova NA, Lisman JE (1995) D1/D5 doapmine receptor activation increases the magnitude of early long-term potentiation at CA1 hippocampal synapses. J Neurosci 16:7478-7486.

Patrick SL, Thompson TL, Walker JM, Patrick RL (1991) Concomitant sensitization of amphetamine-induced behavioral stimulation and in vivo dopamine release from rat caudate nucleus. Brain Res 538:343-346.

Paulson PE, Robinson TE (1995) Amphetamine-induced time-dependent sensitization of dopamine neurotransmission in the dorsal and ventral striatum: a microdialysis study in behaving rats. Synapse 19:56-65.

Richfield EK, Young AB, Penney JB (1987) Comparative distribution of dopamine D1 and D2 receptors in the basal ganglia of turtles, pigeons, rats, cats and monkeys. J Comp Neurol 262:446-463.

Robertson HA (1992) Dopamine receptor interactions: some implications for the treatment of Parkinson's disease. Trends Neurosci 15:201-206.

Robinson TE, Becker JB (1986) Enduring changes in brain and behavior produced by chronic amphetamine administration: a review and evaluation of animal models of amphetamine psychosis. Brain Res Rev 396:157-198.

Robinson TE, Whishaw IQ (1988) Normalization of extracellular dopamine in striatum following recovery from a partial unilateral 6-OHDA lesion of the substantia nigra: a microdialysis study in freely moving rats. Brain Res 450:209-224.

Robinson TE, Jurson PA, Bennett JA, Bentgen KM (1988) Persistent sensitization of dopamine neurotransmission in ventral striatum nucleus accumbens produced by prior experience with $(+)$-amphetamine: a microdialysis study in freely moving rats. Brain Res 462:211-222.

Robinson TE, Mocsary Z, Camp DM, Whishaw IQ (1994) Time course of recovery of extracellular dopamine following partial damage to the nigrostriatal dopamine system. J Neurosci 14:2687-2696.

Steiner H, Bonatz AE, Huston JP, Schwarting R (1988) Lateralizad wall-facing versus turning as measures of behavioral asymmetries and recovery function after injection of 6-hydroxydopamine into the substantia nigra. Exp Neurol 99:556-566.
Stewart J, Druhan JP (1993) Development of both conditioning and sensitization of the behavioral activating effects of amphetamine is blocked by the non-competitive NMDA receptor antagonist, MK-801. Psychopharmacology 110:125-132.

Stewart J, Vezina P (1989) Microinjections of Sch-23390 into the ventral tegmental area and substantia nigra pars reticulata attenuate the development of sensitization to the locomotor activating effects of systemic amphetamine. Brain Res 495:401-406.

Timmerman W, Abercrombie ED (1996) Amphetamine-induced release of dendritic dopamine in substantia nigra pars reticulata: D1-mediated behavioral and electrophysiological effects. Synapse 23:280-291.

Vezina P (1993) Amphetamine injected into the ventral tegmental area sensitizes the nucleus accumbens dopaminergic response to systemic amphetamine: an in vivo microdialysis study in the rat. Brain Res 605:332-337.

Vezina P (1996) D1 dopamine receptor activation is necessary for the induction of sensitization by amphetamine in the ventral tegmental area. J Neurosci 16:2411-2420.

Vezina P, Stewart J (1989) The effect of dopamine receptor blockade on the development of sensitization to the locomotor activating effects of amphetamine and morphine. Brain Res 499:108-120.

Vezina P, Stewart J (1990) Amphetamine administered to the ventral tegmental area but not to the nucleus accumbens sensitizes rats to systemic morphine: lack of conditioned effects. Brain Res 516:99-106.

Waszczak BL, Walters JR (1984) A physiological role for dopamine as modulator of GABA effects in substantia nigra: supersensitivity in 6-hydroxydopamine lesioned rats. Eur J Pharmacol 105:369-373.

Waszczak BL, Walters JR (1986) Endogenous dopamine can modulate inhibition of substantia nigra pars reticulata neurons elicited by GABA iontophoresis or striatal stimulation. J Neurosci 6:120-126.

Wolf ME, Jeziorski M (1993) Coadministration of MK-801 with amphetamine, cocaine or morphine prevents rather than transiently masks the development of behavioral sensitization. Brain Res 613:291-294.

Wolf ME, Khansa MR (1991) Repeated administration of MK-801 produces sensitization to its own locomotor stimulant effects but blocks sensitization to amphetamine. Brain Res 562:164-168.

Wolf ME, White FJ, Hu X (1994) MK-801 prevents alterations in the mesoaccumbens dopamine system associated with behavioral sensitization to amphetamine. J Neurosci 14:1735-1745.

Zhang WQ, Tilson HA, Nanry KP, Hudson PM, Hong JS, Stachowiak MK (1988) Increased dopamine release from striata of rats after unilateral nigrostriatal bundle damage. Brain Res 461:335-342. 